DOI: https://doi.org/10.24127/ajpm.v10i3.3781

\title{
INVESTIGASI STRUKTUR ARGUMEN MAHASISWA DALAM PEMBUKTIAN ALJABAR BERDASARKAN SKEMA TOULMIN
}

\author{
Siti Faizah $^{1 *}$, Novia Dwi Rahmawati ${ }^{2}$ Tatik Retno Murniasih ${ }^{3}$ \\ $1^{*, 2}$ Universitas Hasyim Asy’ari, Jombang, Indonesia \\ ${ }^{3}$ Universitas PGRI Kanjuruhan, Malang, Indonesia \\ ${ }^{*}$ Corresponding author. Jl. Irian Jaya No. 55 Tebuireng Jombang \\ E-mail: $\quad$ faizah.siti91@gmail.com ${ }^{\left.1^{*}\right)}$
}

Received 03 March 2021; Received in revised form 13 September 2021; Accepted 27 September 2021

\begin{abstract}
Abstrak
Penelitian tentang argumen dalam pembuktian matematika penting untuk dikaji karena argumen merupakan pembuktian yang memuat justifikasi secara rasional untuk mendapatkan kesimpulan. Penelitian ini bertujuan untuk menyelidiki struktur argumen mahasiswa ketika menyelesaikan pembuktian aljabar. Penelitian dilakukan kepada mahasiswa Program Studi Pendidikan Matematika Universitas Hasyim Asy'ari. Instrumen yang digunakan untuk mengumpulkan data adalah tes tertulis dan wawancara. Instrumen tes diberikan kepada tiga mahasiswa sebagai subjek penelitian, kemudian dilanjutkan dengan wawancara kepada masing-masing subjek. Subjek penelitian ditentukan dengan cara memilih mahasiswa yang mempunyai kemampuan matematika tinggi, sedang, dan rendah berdasarkan hasil belajar selama mengikuti perkuliahan Aljabar Linier Elementer. Hasil penelitian menunjukkan bahwa mahasiswa melakukan identifikasi masalah untuk menentukan konsep matematika yang berupa definisi atau teorema. Konsep tersebut merupakan warrant dan backing yang dijadikan penjamin untuk melakukan pembuktian dalam bentuk simbol aljabar. Warrant dan backing adalah penjamin yang dapat menghubungkan antara data dengan klaim. Temuan lain dalam penelitian ini juga muncul saat mahasiswa menyadari kesalahan yang dilakukan karena menggunakan konsep invers pada bilangan real, sehingga mahasiswa memunculkan rebuttal yang berfungsi untuk menyangkal argumennya sendiri. Keraguan mahasiswa muncul saat mereview hasil pembuktiannya. Akan tetapi, jika mahasiswa sudah merasa yakin dengan kesimpulan yang diperoleh, maka keyakinan tersebut adalah qualifier yang berupa justifikasi.
\end{abstract}

Kata kunci: Argumen; model Toulmin; pembuktian; struktur.

\begin{abstract}
The study about arguments in mathematical proof is important because those are proofs that contain rational justification to get a conclusion. This study aimed to investigate the structure of students' argument when completing algebraic proof. The research was conducted to the students of the Mathematics Education Study Program of Hasyim Asy'ari University. The instruments used to collect data were written test and interview. It was given to the three students as research subjects, then followed by interview with each subject. The research subject is chosen by selecting students who have high, medium, and low mathematics abilities based on their learning outcomes while attending the Elementary Linear Algebra course. The results showed that students identified problems to determine mathematical concepts in the form of definition or theorem. The concept is a warrant and backing which is used as a guarantor to prove the form of algebraic symbols. Warrants and backings are guarantors that can link data with claim. Another finding in this study was also emerged when students realized their mistakes because they used the inverse concept of real numbers, so the students came up with rebuttals which served to refute their own arguments. Student doubts arise when reviewing the results of the proof. However, if the students already feel confident with the conclusions obtained, then that belief becomes a qualifier in the form of justification.
\end{abstract}

Keywords: Argument; proof; structure; Toulmins'scheme

This is an open access article under the Creative Commons Attribution 4.0 International License 
DOI: https://doi.org/10.24127/ajpm.v10i3.3781

\section{PENDAHULUAN}

Aljabar merupakan salah satu cabang ilmu matematika yang menuntut mahasiswa berpikir secara logis karena dalam aljabar memuat pernyataan matematika yang perlu dibuktikan kebenarannya. Argumen dapat dikatakan sebagai pembuktian karena memuat justifikasi secara rasional terhadap suatu kesimpulan (Pedemonte, 2014). Akan tetapi, tidak semua mahasiswa dapat memberikan kesimpulan secara rasional karena mahasiswa tidak memahami konsep yang akan digunakan. Padahal di sisi lain proses dan konsep merupakan dua hal yang sangat penting dalam matematika karena konsep memuat simbol yang mempunyai makna berdasarkan definisi atau aksioma. (Angel \& Overson, 2016; Hannah et al., 2014).

Beberapa penelitian yang berkaitan dengan pembuktian menyatakan bahwa mahasiswa melakukan trial and error ketika membuktikan kebenaran pernyataan matematika, sehingga tidak muncul aturan matematika yang digunakan sebagai dasar atau penjamin (warrant) (Laamena et al., 2018; Reyhani et al., 2012). Lebih lanjut, kemampuan mahasiswa dalam membuktikan kebenaran proposisi aljabar dilakukan melalui proses kognitif tetapi tidak memperhatikan struktur argumen sebagai produk dari pembuktian (Öztürk \& Kaplan, 2019; Martinez, 2014; Baccaglini-frank et al., 2018).

Berdasarkan hasil penelitian terdahulu menunjukkan bahwa belum banyak penelitian yang membahas tentang eksplorasi terhadap struktur argumen mahasiswa berdasarkan proses berpikir matematis. Oleh karena itu, penelitian ini bertujuan untuk menginvestigasi struktur argumen mahasiswa dalam menyelesaikan pembuktian aljabar berdasarkan proses berpikir matematis agar mahasiswa mampu membuktikan kebenaran suatu pernyataan secara logis dan sistematis.

Struktur argumen dalam pembuktian matematika memuat serangkaian premis dan kesimpulan (Imamoglu \& Togrol, 2015). Investigasi terhadap struktur argumen mahasiswa dapat dilakukan dengan menggunakan skema model Toulmin karena memiliki kelebihan untuk menganalisis argumen formal maupun informal (Simpson, 2015). Skema model Toulmin memuat tiga elemen dasar yakni: (1) Claim (C): pernyataan dari pembicara; (2) Data (D): justifikasi dari claim; dan (3) Warrant (W): aturan yang dapat menghubungkan data dengan klaim. Aturan matematika yang dapat digunakan untuk menghubungkan data dengan klaim adalah definisi, aksioma, atau teorema (Pedemonte, 2014;). Definisi merupakan konsep formal yang dapat dijadikan dasar untuk melakukan pembuktian (Plaxco, 2012). Ketiga komponen tersebut dapat disajikan pada Gambar 1.

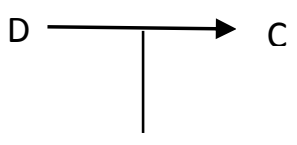

W

Gambar 1. Komponen Dasar Toulmin

Ketiga komponen dasar tersebut didukung dengan komponen lain yang berupa: (1) Qualifier (Q): kekuatan atau keyakinan dari argumen; (2) Rebuttal (R): kondisi pengecualian; dan (3) Backing (B): pendukung aturan untuk warrant (Pedemonte, 2014). Keseluruhan komponen dalam skema argumen model Toulmin dapat dilihat pada Gambar 2. 


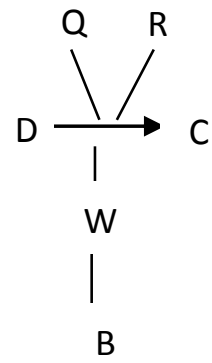

Gambar 2. Skema model Toulmin

Analisis terhadap struktur argumen dalam pembuktian aljabar memang dapat dilakukan dengan menggunakan skema model Toulmin. Akan tetapi, proses berpikir mahasiswa dalam menyusun argumen tidak dapat diamati secara langsung karena mahasiswa tidak selalu menuliskan semua pengetahuannya pada lembar jawaban. Oleh karena itu perlu dilakukan eksplorasi terhadap proses berpikir mahasiswa ketika menyusun argumen matematis melalui teori tiga dunia matematika yang memuat: conceptual-embodied world, proceptual-symbolic world, dan axiomatic-formal world (Tall \& Witzke, 2020).

Conceptual-embodied world adalah dunia perwujudan konsep berdasarkan persepsi dan refleksi. Mahasiswa memikirkan konsep dengan cara memulai dari hal-hal yang bisa dirasakan secara fisik dan juga secara mental. Proceptual-symbolic world merupakan dunia simbolik yang dapat tumbuh melalui aksi ketika melakukan perhitungan dan simbol sebagai konsep yang sedang dipikirkan. Keduanya saling terkait karena proses merupakan aktivitas ketika melakukan sesuatu dan konsep merupakan obyek yang sedang dipikirkan, sehingga keduanya disebut sebagai procept (process and concept).
Axiomatic-formal world merupakan dunia formal aksiomatik yang berupa pengetahuan mahasiswa berdasarkan aksioma, teorema, atau definisi dari suatu obyek formal (Sudirman et al., 2015).

\section{METODE PENELITIAN}

Penelitian ini termasuk dalam jenis kualitatif yang bertujuan untuk mengeksplorasi struktur argumen mahasiswa kemudian dideskripsikan secara naratif. Penelitian ini dilakukan kepada lima belas mahasiswa Prodi Pendidikan Matematika di salah satu perguruan tinggi swasta di Jombang Jawa Timur. Prosedur penelitian dilakukan melalui observasi selama proses perkuliahan aljabar linier elementer, menentukan subjek penelitian, pengambilan data, mengolah data, dan analisis data.

Penelitian dilakukan kepada mahasiswa semester dua yang sedang menempuh mata kuliah aljabar linier elementer, sehingga pemilihan subjek didasarkan pada kemampuan matematika tinggi, sedang, rendah dan juga didasarkan pada kemampuan komunikasi lisan mahasiswa selama mengikuti perkuliahan. Dari hasil observasi diperoleh tiga mahasiswa sebagai subjek penelitian. Ketiga subjek tersebut terdiri dari: satu mahasiswa dengan kemampuan matematika tinggi, satu mahasiswa dengan kemampuan matematika sedang, dan satu mahasiswa dengan kemampuan matematika rendah.

Instrumen utama pada penelitian ini adalah peneliti sendiri dengan dibantu instrumen tes dan wawancara semi terstruktur. Wawancara digunakan sebagai triangulasi untuk mengetahui kesesuaian data yang diperoleh dari hasil tes tertulis dan ungkapan subjek secara lisan terkait proses penyelesaian tes. Wawancara dilakukan dengan 
DOI: https://doi.org/10.24127/ajpm.v10i3.3781

bantuan alat perekam dan catatan lapangan. Alat perekam digunakan untuk merekam perilaku dan ucapan subjek, sedangkan catatan lapangan digunakan untuk mencatat poin penting selama proses pengambilan data.

Teknik pengumpulan data dilakukan dengan cara memberikan instrumen tes pembuktian aljabar kepada masing-masing subjek, kemudian dilanjutkan dengan wawancara berbasis tugas. Tes yang diberikan kepada subjek penelitian diadaptasi dari Anton (2014). Adapun instrumen tes yang digunakan pada penelitian ini adalah: "Tunjukkan bahwa jika sebuah matriks bujur sangkar $A$ memenuhi $A^{2}-3 A+I=0$ $\operatorname{maka} A^{-1}=3 I-A$ !"”

Data yang telah terkumpul dari hasil tes dan wawancara kemudian dianalisis dengan menggunakan teknik analisis data kualitatif, yang meliputi: transkrip data, mengamati data, reduksi data, validasi data, mengkategorikan data, menginterpretasikan data, dan menarik kesimpulan. Reduksi data dilakukan dengan cara memilih dan memfokuskan data yang terksait dengan tujuan penelitian, sedangkan data yang tidak terkait dengan tujuan penelitian dapat dipertimbangkan sebagai temuan penelitian. Validasi data dilakukan dengan cara menyesuaikan hasil tes tertulis dengan hasil wawancara. Validasi data dapat dikatakan sebagai triangulasi karena validitas dan reliabilitas pada penelitian kualitatif dapat dilihat dari kesesuaian data yang diperoleh. Sedangkan interpretasi data dilakukan dengan memaparkan data yang diperoleh dari hasil tes tertulis dan transkrip wawancara yang telah direduksi, sehingga mempermudah dalam penarikan kesimpulan. Analisis terhadap struktur argumen mahasiswa dalam penelitian ini mengacu pada Tabel

Tabel 1. Investigasi struktur argumen berdasarkan skema Toulmin dan teori tiga dunia matematika

\begin{tabular}{|c|c|}
\hline Tiga Dunia Matematika & Deskripsi \\
\hline $\begin{array}{l}\text { Conceptual-embodied } \\
\text { world }\end{array}$ & $\begin{array}{l}\text { - Memahami fenomena yang dirasakan untuk menggali informasi } \\
\text { yang terkait dengan data dan klaim } \\
\text { - Mengidentifikasi data dan klaim melalui persepsi dan refleksi }\end{array}$ \\
\hline $\begin{array}{l}\text { Proceptual-symbolic } \\
\text { world }\end{array}$ & $\begin{array}{l}\text { - Menentukan aturan matematika sebagai konsep yang dapat } \\
\text { menghubungkan data dan klaim. } \\
\text { - Melakukan perhitungan atau operasi aljabar berdasarkan konsep } \\
\text { yang sedang dipikirkan }\end{array}$ \\
\hline Axiomatic-formal world & $\begin{array}{l}\text { - Melakukan perhitungan dengan menggunakan simbol yang } \\
\text { terkait dengan definisi, aksioma, atau teorema yang terdapat } \\
\text { pada konsep } \\
\text { - Jika konsep yang digunakan tidak cukup kuat untuk } \\
\text { menghubungkan data dan klaim, maka dapat muncul } \\
\text { penyangkal (rebuttal). }\end{array}$ \\
\hline
\end{tabular}

HASIL DAN PEMBAHASAN

Berdasarkan hasil belajar mahasiswa selama menempuh mata kuliah Aljabar Linier Elementer menunjukkan bahwa S1 sebagai subjek dengan kemampuan matematika tinggi, S2 sebagai subjek dengan kemampuan matematika sedang, dan S3 sebagai subjek dengan kemampuan matematika rendah. Ketiga subjek tersebut 
menyelesaikan instrumen tes dengan cara membuktikan tetapi tidak semua subjek melakukan pembuktian secara formal. Adapun hasil eksplorasi kepada masing-masing subjek adalah sebagai berikut:

\section{Subjek 1 (S1)}

S1 menyelesaikan masalah pada instrumen tes dengan cara membuktikan. S1 menyusun argumen dalam pembuktian berdasarkan konsep skalar dan matriks identitas.

S1 memahami soal pada instrumen tes dengan cara melakukan identifikasi masalah. S1 menyebutkan bahwa pada pernyataan tersebut memuat dua persamaan yang bersifat sama tetapi mempunyai syarat yang berupa "jika A memenuhi persamaan kedua, maka A juga memenuhi persamaan pertama, begitupun sebaliknya". Persamaan pertama berbentuk $A^{-1}=3 I-A$ dan persamaan kedua berupa $A^{2}-3 A+I=0$. Dari ungkapan subjek dapat diketahui bahwa kedua persamaan tersebut merupakan data dan klaim yang perlu dibuktikan kebenarannya. Subjek menganggap bahwa pembuktian dapat dilakukan dengan menggunakan salah satu persamaan karena keduanya sama-sama memuat I sebagai matriks identitas, dalam hal ini subjek memilih persamaan kedua untuk dibuktikan.

S1 melakukan operasi aljabar terhadap $I$ sebagai matriks identitas dengan menggunakan pengetahuannya tentang konsep matriks identitas yang berupa "sebuah matriks identitas memiliki peran yang sama dalam aritmatika matriks, misalkan sebuah skalar $a$ yang berperan dalam hubungan numerik $a \cdot I=I . a=a$ ". Selanjutnya, subjek memindahkan $I$ dari ruas kiri ke ruas kanan kemudian mengalikan skalar 3 dengan $I$. Hal ini dilakukan subjek karena dia mengetahui kalau pada konsep matriks identitas disebutkan bahwa $a . I=a$ sehingga $3 . I=3$. Dari operasi aljabar yang dilakukan subjek pada langkah pertama menghasilkan $A(A-3 I)=-I$.

S1 melakukan operasi aljabar pada langkah berikutnya dengan menggunakan konsep invers perkalian pada bilangan real yang berupa "jika $A \cdot A^{-1}=I$ maka $A^{-1}=\frac{I}{A}$, padahal dalam hal ini subjek menentukan invers pada matriks dan bukan pada bilangan real, tetapi subjek tidak menyadari hal itu. Subjek menggunakan pengetahuannya tentang konsep invers pada bilangan real secara intuitif karena dia menganggap bahwa invers pada bilangan real juga berlaku pada matriks.

S1 baru menyadari bahwa penggunaan $A^{-1}=\frac{I}{A}$ adalah tidak tepat ketika proses wawancara. Pada saat wawancara subjek mengatakan bahwa dia ragu ketika menggunakan konsep invers bilangan real untuk menentukan $A^{-1}=\frac{I}{A}$ karena dia belum pernah menemukan teorema atau definisi yang menyatakan bahwa invers pada bilangan real berlaku pula pada matriks. S1 menuliskan $\quad A A^{-1}=I$ maka $A^{-1}=\frac{I}{A}$ sebagai dasar atau penjamin untuk mendapatkan $A^{-1}$ (Gambar 3).

$\begin{aligned} A^{2}-3 A+I & =0 \\ A^{2}-3 A & =-I \\ A(A-3 I) & =-I \\ A-3 I & =\frac{-I}{A} \Rightarrow f \text { yi } A \cdot A^{-1}=I \text { maka } A^{-1}=\frac{I}{A} \\ A-3 I & =-A^{-1} \\ A^{-1} & =3 I-A \Rightarrow \text { terbukti }\end{aligned}$

Gambar 3. Hasil pembuktian S1

S1 melakukan pembuktian dengan menggunakan aturan matematika yang berupa konsep skalar pada matriks, 
matriks identitas, dan invers sebagai penjamin (warrant) untuk menguraikan suatu pembuktian agar diperoleh argumen yang valid. Akan tetapi, dia menggunakan pengetahuan yang tidak tepat terkait invers suatu matriks dengan menggunakan konsep invers bilangan real untuk mendapatkan kesimpulan yang berupa "suatu matriks bujur sangkar A memenuhi $A^{2}-3 A+I=0$ maka berlaku $A^{-1}=3 I-A$ adalah terbukti benar".

Jika dilihat dari kesimpulan yang diberikan oleh subjek 1 maka kesimpulannya benar, tetapi langkahlangkah pembuktiannya tidak tepat karena dia menggunakan $A^{-1}=\frac{I}{A}$ untuk mendapatkan $\quad A^{-1}=3 I-A$. Oleh karena itu, subjek 1 memunculkan rebuttal untuk menyangkal argumennya sendiri. Rebuttal muncul karena subjek merasa ragu-ragu dengan argumen yang dibentuk ketika melakukan pembuktian.

\section{Subjek 2 (S2)}

S2 memahami fenomena yang ada pada pernyataan dengan berfokus pada matriks bujur sangkar, misalkan terdapat matriks bujur sangkar A yang memenuhi $A^{2}-3 A+I=0 \quad$ maka matriks bujur sangkar A juga memenuhi $A^{-1}-1=3 I-A$.

Subjek mengidentifikasi data dan klaim dengan cara mengklasifikasi menadi tiga, yakni: matriks bujur sangkar $\mathrm{A}$, matriks $A^{-1}$ dan matriks identitas. Subjek memisalkan matriks bujur sangkar $A=\left(\begin{array}{ll}2 & 1 \\ 2 & 1\end{array}\right)$ untuk disubstitusikan ke $A^{2}-3 A+I=0 . \quad$ Kemudian S2 menentukan $A^{-1}$ dengan menggunakan adjoin (adj) dan juga menggunakan matriks identitas yang berupa $I=$ $\left(\begin{array}{ll}1 & 0 \\ 0 & 1\end{array}\right)$ seperti pada Gambar 4 .

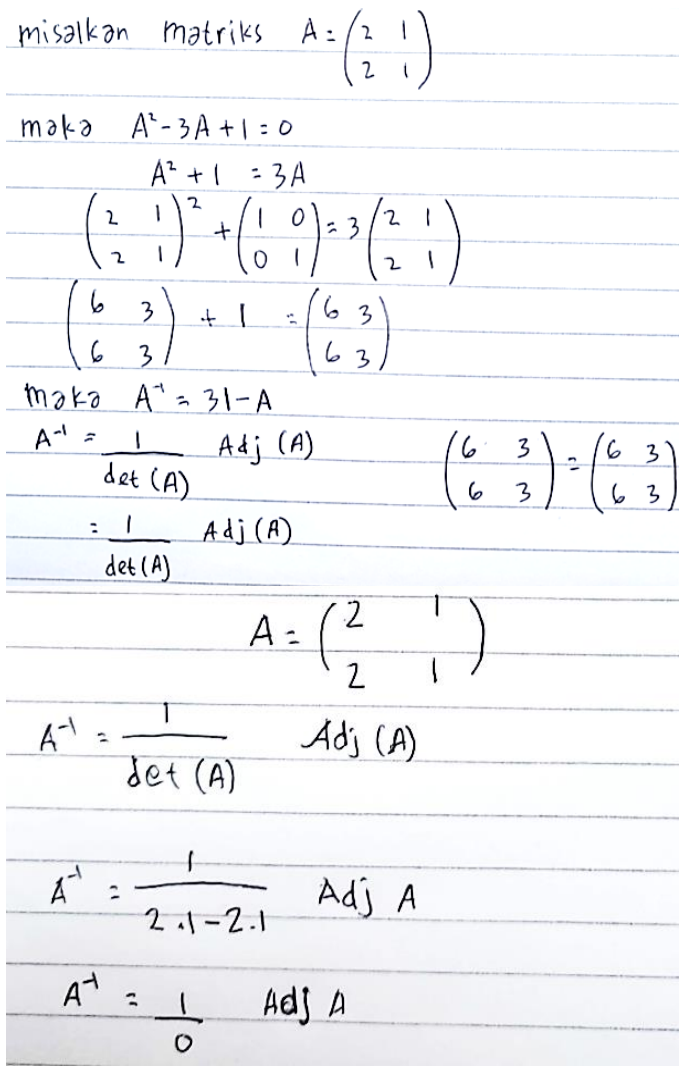

Gambar 4. Hasil pembuktian Subjek 2

S2 mensubstitusikan pemisalan $A=\left(\begin{array}{ll}2 & 1 \\ 2 & 1\end{array}\right)$ ke bentuk $A^{2}-3 A+I=$ 0 sehingga diperoleh $\left(\begin{array}{ll}6 & 3 \\ 6 & 3\end{array}\right)$. Setelah itu subjek mencari $A^{-1}$ dengan menggunakan teorema yang berupa "jika A adalah suatu matriks yang dapat dibalik (invers), maka $A^{-1}=$ $\frac{1}{\operatorname{det}(A)} \operatorname{adj}(A)$ ". Kemudian subjek mensubstitusikan matriks bujur sangkar $A=\left(\begin{array}{ll}2 & 1 \\ 2 & 1\end{array}\right)$ ke teorema tersebut. Hasil substitusi menunjukkan bahwa $A^{-1}=$ $\frac{1}{0} \operatorname{adj}(A)$, sehingga dia memberikan klaim yang berupa " $A^{-1}$ tidak bisa ditemukan karena $\operatorname{det}(A)=\frac{1}{0} "$. Dari hasil pembuktiannya tersebut, subjek tidak bisa melanjutkan ke langkah pembuktian selanjutnya karena dia memiliki persepsi kalau langkahlangkah pembuktiannya salah. Subjek mengatakan bahwa kesalahannya 
DOI: https://doi.org/10.24127/ajpm.v10i3.3781

terletak pada $\left(\begin{array}{ll}2 & 1 \\ 2 & 1\end{array}\right)^{2}=\left(\begin{array}{ll}6 & 3 \\ 6 & 3\end{array}\right)$, sehingga dia tidak bisa memberikan kesimpulan dari hasil pembuktiannya.

Dari hasil eksplorasi yang kepada subjek 2 diperoleh temuan bahwa subjek 2 mengidentifikasi data dan klaim dengan cara mengklasifikasikan menjadi tiga bagian. S2 menggunakan aturan yang berupa teorema invers matriks yang memuat adjoin (adj) sebagai dasar untuk menguraikan pembuktian agar diperoleh argumen yang valid, akan tetapi subjek mengalami kesalahan sehingga ia tidak bisa memberikan kesimpulan dari hasil pembuktiannya. Aturan matematika yang berupa teorema dapat dikatakan sebagai warrant atau penjamin dari suatu argumen, kemudian didukung oleh backing yang berupa substitusi matriks bujur sangkar A ke dalam teorema.

\section{Subjek 3 (S3)}

S3 memberikan pembuktian tanpa menggunakan warrant atau penjamin apapun. Subjek 3 memahami dengan cara mengidentifikasi pernyataan yang memuat matriks bujur sangkar A yang memenuhi $A^{2}-3 A+I=0$. Subjek memisalkan matriks bujur sangkar $A=\left(\begin{array}{ll}2 & 4 \\ 3 & 0\end{array}\right)$ dan $I=\left(\begin{array}{ll}1 & 0 \\ 0 & 1\end{array}\right)$ sebagai matriks identitas. Setelah itu subjek melakukan perhitungan dengan cara mensubstitusikan hasil pemisalannya ke $3 I-A$ dan $A-3 I$. Dalam hal ini subjek 3 memunculkan $A-3 I$ padahal dalam instrumen tes tidak menyebutkan $A-3 I$ sama sekali. Subjek 3 dapat memunculkan $A-3 I$ karena dia memahami kalau invers adalah kebalikan, sehingga kebalikan dari $A^{-1}=3 I-A$ adalah $A^{-1}=A-3 I$. S3 memperoleh $3 I-A=A-3 I$ dari hasil substitusi seperti yang terdapat pada Gambar 5.

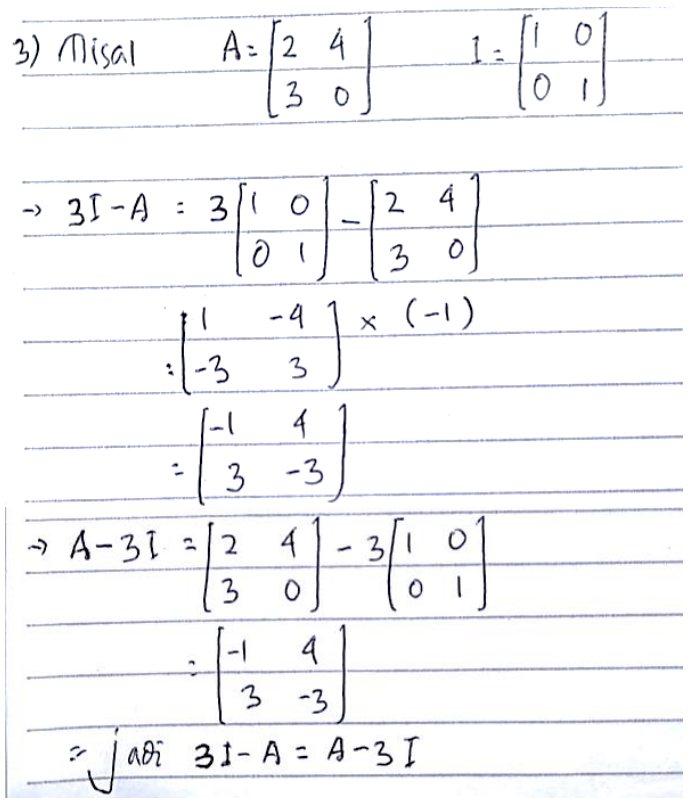

Gambar 5. Hasil Pembuktian S3

Subjek 3 melakukan perhitungan tanpa memperhatikan hasil identifikasi masalah yang telah dilakukan di awal. Pada saat identifikasi masalah, subjek tidak menyebutkan $A-3 I$ sama sekali tetapi ketika melakukan perhitungan subjek menggunakan $3 I-A$ dan $A-3 I$. Hal ini dikarenakan subjek hanya berpedoman pada $A^{-1}=3 I-A$ untuk melakukan pembuktian dan tidak memperhatikan $\quad A^{2}-3 A+I=0$. Subjek tidak melakukan operasi aljabar untuk menguraikan pembuktian.

Berdasarkan hasil eksplorasi dan investigasi kepada masing-masing subjek penelitian diperoleh temuan bahwa identifikasi merupakan langkah awal yang dilakukan mahasiswa dalam memahami masalah. Hal ini sejalan dengan penelitian terdahulu yang menyebutkan bahwa indentifikasi (indentifying) merupakan langkah awal dalam memahami masalah pembuktian (Wayan Puja Astawa et al., 2018; Faizah et al., 2020a). Akan tetapi, penelitian terdahulu belum mengungkap tentang struktur argumen yang terdapat pada pembuktian matematika. Padahal argumen merupakan hasil dari 
merekonstruksi pengetahuan yang dimiliki mahasiswa berdasarkan proses berpikir yang dilakukan (Alcolea Banegas, 2013).

Identifikasi masalah dilakukan mahasiswa dengan cara mengklasifikasikan menjadi beberapa objek untuk mengetahui data dan klaim yang akan dibuktikan. Mahasiswa menggunakan pengetahuan atau pengalaman yang dimiliki terkait konsep matematika yang akan digunakan (Tall et al., 2013). Mahasiswa dapat menentukan konsep yang terkait dengan data dan klaim melalui dunia perwujudan (Conceptualembodied world) yang terdapat pada instrumen tes. Mahasiswa menggunakan konsep skalar pada matriks, invers matriks, matriks identitas dan juga adjoin matriks.

Penggunaan teorema tentang invers matriks dan konsep perkalian skalar merupakan aturan matematika yang dijadikan dasar untuk menguraikan suatu pembuktian. Aturan tersebut adalah warrant dan backing yang berfungsi sebagai penjamin untuk mengetahui keterkaitan antara data dengan klaim (Metaxas et al., 2016). Mahasiswa menggunakan warrant dan backing untuk menguraikan pembuktian dalam bentuk simbol aljabar, sehingga pada tahap ini mahasiswa menggunakan dunia simbolik (proceptual-symbolic world) untuk mendapatkan pembuktian yang bersifat formal (Axiomatic-formal world).

Warrant dalam suatu argumen juga dapat berupa definisi atau analogi terhadap suatu konsep matematika (Nardi et al., 2014). Warrant dan backing dapat juga dijadikan sebagai alasan untuk memperkuat keyakinan mahasiswa terhadap hasil pembuktian yang berupa kesimpulan (Faizah et al., 2020b). Ketika mahasiswa merasa ragu dengan aturan matematika yang digunakan, maka keraguran tersebut dapat dikatakan sebagai rebuttal karena mahasiswa merasa konsep yang digunakan tidak tepat (Lambert \& Bleicher, 2016).

Hasil temuan penelitian menunjukkan bahwa semua komponen Toulmin yang terdiri dari data, claim, warrant, backing, qualifier, dan rebuttal muncul dalam struktur argumen mahasiswa ketika melakukan pembuktian aljabar. Akan tetapi pada penelitian terdahulu menyebutkan bahwa rebuttal tidak selalu muncul dalam argumen matematika (Lin, 2018). Hal ini dikarenakan tidak semua argumen dalam pembuktian matematika memerlukan penyangkal

Keyakinan mahasiswa terhadap hasil pembuktian matematika dapat ditunjukkan dengan adanya qualifier sebagai justifikasi dari hasil pembuktian (Wagner et al., 2013). Perbedaan lain juga terletak pada kemampuan mahasiswa dalam menyusun struktur argumen matematis melalui teori tiga dunia matematika yang memuat dunia perwujudan, dunia simbolik, dan dunia formal.

\section{KESIMPULAN DAN SARAN}

Struktur argumen mahasiswa dalam pembuktian aljabar dapat terbentuk melalui: dunia perwujudan, dunia simbolik, dan dunia formal. Mahasiswa mengidentifikasi masalah yang akan dibuktikan terlebih dahulu dengan cara menentukan data dan klaim. Identifikasi masalah juga berfungsi untuk menentukan definisi atau teorema yang akan digunakan sebagai dasar dalam menguraikan setiap langkah pembuktian. Definisi atau teorema tersebut merupakan warrant dan backing yang mempunyai kedudukan sebagai penjamin dalam suatu argumen. 
Temuan lain juga muncul saat mahasiswa menyadari kesalahan yang dilakukan karena menggunakan konsep yang tidak tepat, sehingga muncul rebuttal yang berfungsi untuk menyangkal argumen yang telah dibentuk. Keraguan mahasiswa muncul ketika mereview kembali hasil pembuktiannya. Akan tetapi, jika mahasiswa sudah yakin, maka keyakinan tersebut adalah qualifier.

Berdasarkan hasil penelitian dapat diketahui bahwa penelitian lanjutan yang direkomdasikan adalah investigasi terhadap struktur argumen mahasiswa melalui pembuktian kontradiksi. Hal ini dilakukan agar dapat diketahui bentuk rebuttal yang terkait dengan konsep matematika yang digunakan sebagai penjamin dalam suatu argumen.

\section{DAFTAR PUSTAKA}

Alcolea Banegas, J. (2013). Argumentation in mathematics. The Argument of Mathematics, 47-60.

https://doi.org/10.1007/978-94007-6534-4_4

Angel, M., \& Overson, S. (2016). Zambian university student teachers' conceptions of algebraic proofs. Journal of Education and Practic, 7(32), 157-171. https://files.eric.ed.gov/fulltext/EJ 1122465.pdf

Anton, H. \& Rorre, C., (2014). Elementary Linear Algebra $11^{\text {th }}$ edition. United State of America: Wiley.

Baccaglini-frank, A., Antonini, S., Leung, A., \& Mariotti, M. A. (2018). From Pseudo-Objects in Dynamic Explorations to Proof by Contradiction. Digit Exp Math Educ, Springer, https://doi.org/10.1007/s40751018-0039-2
Faizah, S., Nusantara, T., Sudirman, \& Rahardi, R. (2020a). The construction of explicit warrant derived from implicit warrant in mathematical proof. AIP Conference Proceedings, 2215(April). https://doi.org/10.1063/5.0000517 Faizah, S., Nusantara, T., Sudirman, S., \& Rahardi, R. (2020b). Exploring students 'thinking process i $\mathrm{n}$ mathematical proof of abstract algebra based on $\mathrm{M}$ ason ' $\mathrm{s}$ framework. Journal for the Education of Gifted Young Scientist. 8(June), 871-884.

Hannah, J., Stewart, S., \& Thomas, M. (2014). Teaching Linear Algebra in the Embodied, Symbolic and Formal Worlds of Mathematical Thinking: Is There a Preferred Order? Pme 38, 3, 241-248.

Imamoglu, Y., \& Togrol, A. Y. (2015). Proof Construction and Evaluation Practices of Prospective Mathematics Educators. European Journal of Science and Mathematics Education 3(2), 130-144.

Laamena, C. M., Nusantara, T., Irawan, E. B., \& Muksar, M. (2018). How do the Undergraduate Students Use an Example in Mathematical Proof Construction: A Study based on Argumentation and Proving Activity. Intenational Electronic Journal of Mathematics Education,13(3), 185-198.

Lambert, J. L., \& Bleicher, R. E. (2016). Argumentation as a Strategy for Increasing Preservice Teachers' Understanding of Climate Change, a Key Global Socioscientific Issue. International Journal of Education in Mathematics, 
DOI: https://doi.org/10.24127/ajpm.v10i3.3781

Science and Technology, 5(1), 101. https://doi.org/10.18404/ijemst.21 523

Lin, P. J. (2018). The development of students $\hat{E}$ mathematical argumentation in a primary classroom. Educacao and Realidade, 43(3), 1171-1192. https://doi.org/10.1590/2175623676887

Martinez, M. V. (2014). Algebra and Proof in High School: The Case of Algebraic Proof as Discovery. Redimat, 3(1), 30-53. https://doi.org/10.4471/redimat.20 14.39

Metaxas, N., Potari, D., \& Zachariades, T. (2016). Analysis of a teacher's pedagogical arguments using Toulmin's model and argumentation schemes. Educational Studies in Mathematics, 93(3), 383-397. https://doi.org/10.1007/s10649016-9701-z

Nardi, E., Biza, I., \& Watson, S. (2014). What makes a claim an acceptable mathematical

rgument in the secondary classroom? A preliminary analysis of teachers' warrants in the context of an Algebra Task. Proceedings of the $8^{\text {th }}$ British Congress of Mathematics Education. 1958, 247-254.

Öztürk, M., \& Kaplan, A. (2019). Cognitive analysis of constructing algebraic proof processes: A mixed method research * Egitim ve Bilim, 44(197), 25-64. https://doi.org/10.15390/EB.2018. 7504

Pedemonte, B. (2014). How can the relationship between argumentation and proof be analysed? Educ. Stud. math.
August.

https://doi.org/10.1007/s10649-

006-9057-x

Plaxco, D. (2012). Relationships between Mathematical Proof and Definition. North American Chapter of the International Group for the Psychology of Mathematics Education.

Reyhani, E., Hamidi, F., \& Kolahdouz, F. (2012). A study on algebraic proof conception of high school second graders. Procedia - Social and Behavioral Sciences, 31(2011), 236-241. https://doi.org/10.1016/j.sbspro.20 11.12 .048

Simpson, A. (2015). The anatomy of a mathematical proof: Implications for analyses with Toulmin's scheme. Educational Studies in Mathematics, 90(1), 1-17. https://doi.org/10.1007/s10649015-9616-0

Sudirman, S., Subanji, S., Sutawidjaja, A., \& Muksar, M. (2015). Proses Berpikir Mahasiswa Dalam Mengonstruksi Konsep Komposisi Fungsi. Jurnal Pendidikan Sains (JPS), 3(1), 158-168.

http://journal.um.ac.id/index.php/j ps/article/view/4966

Tall, D., Nogueira, R., \& Healy, L. (2013). Evolving a Three - World Framework for Solving Algebraic Equations in the Light. 1-23.

Tall, D, \& Witzke, I. (2020). Making Sense of Mathematical Thinking over the Long Term: The Framework of Three Worlds of Mathematics and New Developments. MINTUS: Beiträge Zur Mathematischen, Naturwissenschaftlichen Und Technischen Bildung, April. 
DOI: https://doi.org/10.24127/ajpm.v10i3.3781

Wagner, P. A., Smith, R. C., Conner, A., Francisco, R. T., \& Singletary, L. (2013). Using Toulmin's Model to Develop Prospective Teachers' Conceptions of Collective Argumenation. Teaher Education and Knowledge: Research Report. North American Chapter of the International Group for the Psychology of Mathematics Education., 725-732.

Wayan Puja Astawa, I., Ketut Budayasa, I., \& Juniati, D. (2018). The process of student cognition in constructing mathematical conjecture. Journal on Mathematics Education, 9(1), 1525.

https://doi.org/10.22342/jme.9.1.4 278.15-26 